\section{Cultura y Caja Madrid firman un convenio para intervenir en la Iglesia del Santo Cristo de la Salud de Málaga}

La Consejería de Cultura firmó el pasado septiembre un convenio de colaboración con la Fundación Caja Madrid para la restauración del programa iconográfico de la Iglesia del Santo Cristo de la Salud de Málaga, formado por una valiosa colección de bienes muebles de interés cultural. Para la realización de este proyecto de conservación la Consejería aportará el 36\% del coste total de la operación, mientras que la Fundación Caja Madrid asumirá el 64\%. EI IAPH llevará a cabo la investigación previa y la redacción del proyecto.

La Consejería de Cultura de la Junta de Andalucia y el Instituto Andaluz del Patrimonio Histórico han firmado un convenio de colaboración con la Fundación Caja Madrid y el Obispado de la Diócesis de Málaga para la redacción y ejecución de un proyecto de intervención en el programa iconográfico de la Iglesia del Santo Cristo de la Salud de Málaga.

Se trata de un bien de interés cultural representativo de la arquitectura manierista en España, con un enorme valor como documento construido de los principios teológicos de la contrarreforma religiosa a finales del s. XVI y por su trascendente programa iconográfico sobre el martirologio planificado para la iglesia del colegionoviciado de la Compañía de Jesús, apenas treinta y ochos años después de su fundación. Está constituido por $571 \mathrm{~m}^{2}$ de pinturas murales de santos mártires enmarcados en una arquitectura fingida, siete retablos que ilustran los diversos cambios de advocación y dieciséis esculturas asociadas a las hornacinas de los paramentos. A su extenso programa iconográfico se suman los valores de una innovadora concepción de planta centralizada y una importante presencia urbana, dada su ubicación estratégica en las proximidades de la Plaza Mayor de la ciudad. La persistencia en el uso cultual como iglesia de referencia en la ciudad atestigua asimismo el valor social y antropológico de este edificio como patrimonio inmaterial.
El proyecto viene motivado por el mal estado de conservación del bien ya que desde 1964 hasta 1995 se ha actuado en cinco ocasiones pero sin abordar la intervención integral del edificio y los bienes muebles asociados, no habiéndose frenado las causas de deterioro. Por ello se proponen actuaciones complementarias, principalmente en las cubiertas y la fachada. Como primer resultado, se espera la conservación y restauración de dichos bienes. Además se pretende su puesta en valor a través de un nuevo sistema de iluminación monumental y el acondicionamiento del espacio interior. Por último, se plantea como actuación singular la recuperación de unas pinturas murales del siglo XVII que hasta ahora han permanecido ocultas y esperan descubrirse en una segunda fase de estos trabajos.

El documento está siendo redactado por un equipo interdisciplinar del IAPH siguiendo la metodología de estudio e intervención consolidada en los últimos veinte años, desde el principio de "conocer para intervenir". Se han iniciado los estudios previos necesarios para un mejor conocimiento del bien y un diagnóstico del estado de conservación, a partir de los cuales se establecerán los criterios específicos de intervención y se planificarán las actuaciones necesarias en los próximos tres años.

Conforme al Plan de Comunicación y Difusión que viene desarrollando la Fundación
Caja Madrid en su Programa de Conservación del Patrimonio Histórico Español, se recopilará documentación videográfica, se organizarán jornadas divulgativas y se publicarán los resultados en una monografía, entre otras iniciativas, para implicar a la ciudadanía en los procesos.

Este proyecto será una oportunidad única de aumentar el conocimiento del bien no sólo desde el punto de vista material sino del entendimiento de su significado cultural, identidad social, intenciones de proyecto y otras valoraciones culturales.

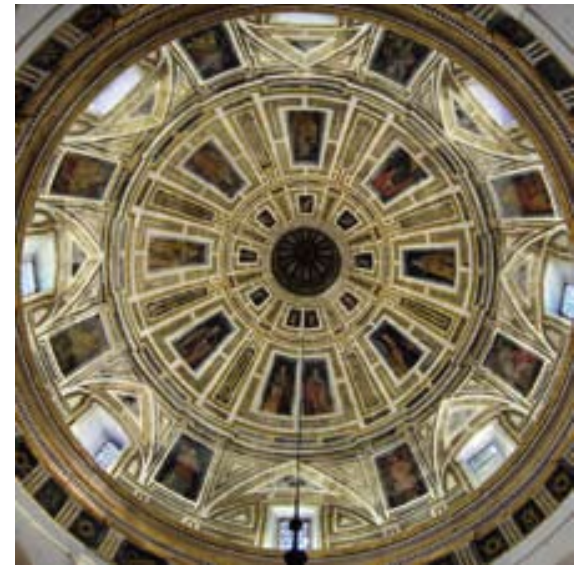

Cúpula de la Iglesia del Santo Cristo de la Salud. Foto: José Manuel Santos Madrid, IAPH

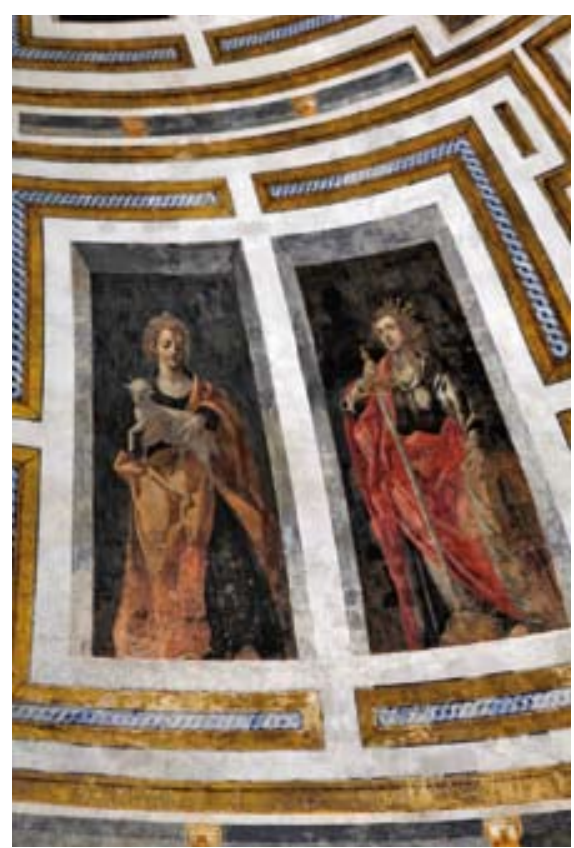

Detalle de las pinturas murales de los santos mártires. Foto: José Manuel Santos Madrid, IAPH

Aurora Villalobos Gómez

Centro de Intervención del IAPH 